\title{
¿Un sistema con vocación de reforma?: La Ley de Responsabilidad Penal de los Menores
}

\author{
Esther Fernández Molina \\ Cristina Rechea Alberola \\ Centro de Investigación en Criminología \\ Universidad de Castilla-La Mancha
}

\section{RESUMEN}

Cuando en el año 2000 se publicó la LO 5/2000 de 12 de enero, reguladora de la responsabilidad penal de los menores, se presentó como el texto definitivo que habría de devolver la estabilidad al ámbito de la política criminal española de jóvenes y menores. Sin embargo, cuando está a punto de acabar el año en el que se celebran los cinco años de vigencia de la Ley, se ultima la que es ya la cuarta reforma que el sistema de justicia de menores español ha sufrido desde entonces.

Tal y como se pone de manifiesto en este artículo, aunque los datos oficiales sobre delincuencia juvenil no evidencian un aumento significativo de las cifras, el legislador, tal y como ha declarado en el Proyecto de Ley, sí lo cree y con la intención de frenar ese aumento ha previsto modificaciones legislativas. Esos cambios han supuesto la adopción de nuevos criterios para la aplicación de las medidas y la incorporación definitiva de la víctima a un sistema que debería estar presidido exclusivamente por el interés del menor. Por otra parte, los resultados de la aplicación práctica de la Ley presentados en este artículo permiten concluir que las tendencias están cambiando y que la práctica judicial durante estos cinco años ha acabado contaminándose del clima más punitivo que parece prevalecer en toda la política criminal del país.

Palabras clave: responsabilidad penal de los menores, justicia juvenil, delincuencia juvenil, política criminal

\section{ABSTRACT}

The 5/2000 Act that regulates the penal responsibility of juveniles was published the 12 of January 2000. This Act was presented as the definite text that could rend stability to the juvenile Spanish criminal policy. Nevertheless, after five years we are contemplating its fourth reform.

Although there is no evidence of any significant increment in the official data of juvenile delinquency, the legislator tries to stop a fictitious rise of this kind of behaviour with the proposal of new legal modifications. These modifications mean to use new criteria to apply the measures and the definite incorporation of the victims to a system that should be prevailed exclusively by the minor's interest.

Looking at the practical application of the law, showed in this paper, we could conclude that tendencies are changing, and that the judicial practice during the last five years has become contaminated by the more punitive climax that is pervading the criminal policy of the country.

Key words: criminal policy, juvenile justice system, juvenile delinquency

Revista Española de Investigación Criminológica

Artículo 4, Número 4 (2006) $\quad$ www.criminología.net

ISSN: $1696-9219$ 


\section{Introducción}

Cuando en 1992 se publicó la L.O. 4/1992, de 5 de junio, reformadora del procedimiento y la competencia de los Juzgados de menores se afirmó que era un texto que nacía con vocación de reforma urgente y provisional y que el sistema de justicia de menores español debía ser inmediatamente reformado. Sin embargo, esa provisionalidad se mantuvo en el tiempo y el sistema permaneció inalterable durante 8 años más.

A comienzos del año 2000 cuando se publicó la LO 5/2000 de 12 de enero, reguladora de la responsabilidad penal de los menores (LORPM) todo el mundo se felicitó por contar ya con ese texto definitivo que habría de devolver la estabilidad a un ámbito crucial dentro de la política-criminal del país y que se presentaba con una absoluta vocación de permanencia. Sin embargo, cuando está a punto de acabar el año en el que se celebran los cinco años de vigencia de la Ley, se ultima la que es ya la cuarta reforma que el sistema de justicia de menores español ha sufrido desde entonces.

La situación parece cuanto menos paradójica y carente de sentido. No obstante, las cosas no son siempre lo que parecen. Aunque, efectivamente, el sistema que define la LORPM ha sido modificado en varias ocasiones, la mayoría de las reformas han producido un gran efecto en el sentimiento de la ciudadanía respecto a los jóvenes y menores que cometen delitos, pero han afectado mínimamente a la dinámica del sistema. Ello se debe en gran parte, a que estas reformas han sido solo una muestra más de la legislación de carácter simbólico que se ha desarrollado en el ámbito de la políticacriminal española en las dos últimas legislaturas y que nos ponen en relación con las nuevas dinámicas que ha generado el nuevo contexto social, político y económico de principios del siglo XXI, cuyo alcance es imposible siquiera de esbozar en este trabajo.

Aunque estas reformas han dejado al sistema prácticamente inalterable en su práctica diaria, sus efectos han ido socavando lentamente parte de la esencia de esta jurisdicción, en la medida que han tenido que incorporar a la víctima dentro de un proceso supuesta y exclusivamente presidido por el interés del menor, y porque ha tenido que excluir de su genuino ámbito de actuación a un grupo de la población de 
infractores juveniles que generan un gran miedo y desconfianza a la sociedad ${ }^{1}$. En efecto, el denominado núcleo duro de la delincuencia juvenil (delincuentes violentos y reincidentes) ha sido sucesivamente presentado a la ciudadanía, de un modo bastante cuestionable, por cierto, como un grupo de población que escapa del ámbito de control del sistema de justicia de menores por los numerosos huecos de impunidad que deja una ley excesivamente benévola.

En los últimos meses el Proyecto de Ley de reforma de la LORPM $^{2}$ que en estos momentos se debate en el Senado y que deriva de la exigencia introducida en la Disposición Adicional Sexta de la última reforma de $2003^{3}$, ha previsto las medidas oportunas para sancionar con más firmeza y eficacia los hechos delictivos más graves. El texto justificando esta decisión en el considerable aumento de los delitos cometidos por menores que han contribuido a desgastar la credibilidad de la Ley, plantea la revisión de algunos aspectos. Nuevamente, esta reforma deja inalterable la mayor parte de actuaciones llevadas a cabo en el sistema y, además de revisar algunas cuestiones que era necesario atender y que los cinco años de vigencia habían constatado, vuelve a centrarse primordialmente en dos aspectos básicos: las reglas de aplicación de las medidas judiciales por parte del Juez y la participación de la víctima en el proceso.

En este artículo se va a ofrecer una visión general del sistema de justicia de menores español. En un primer momento se cuestionará el pretendido aumento de la delincuencia juvenil utilizado una y otra vez como pretexto para justificar las reformas, después se hará una somera exposición de las claves de nuestro sistema y su funcionamiento, y el resultado de su aplicación, al tiempo que se analizarán brevemente las reformas que el Proyecto de Ley prevé.

\section{Tendencias de la delincuencia juvenil en España}

En este apartado se va a exponer la evolución de la delincuencia juvenil para comprobar a qué conclusiones se puede llegar al respecto, a la vista de un análisis

\footnotetext{
${ }^{1}$ Un análisis más amplio puede consultarse en Fernández Molina (en prensa) y en Bernuz y Fernández Molina (2006)

${ }^{2}$ Boletín Oficial de las Cortes Generales. Congreso de los Diputados. VII Legislatura. Proyecto de Ley Orgánica por la que se modifica la Ley Orgánica 5/2000, de 12 de enero, reguladora de la responsabilidad penal de los menores (121/000076).

${ }^{3}$ LO 15/2003, de 25 de noviembre, por la que se modifica la Ley Orgánica 10/1995, de 23 de noviembre, del Código Penal
}

Revista Española de Investigación Criminológica

Artículo 4, Número 4 (2006) $\quad$ www.criminología.net

ISSN: $1696-9219$ 
sosegado de los datos oficiales. En el sistema español se pueden obtener cifras oficiales sobre delincuencia juvenil de tres fuentes distintas: el Ministerio del Interior (MIR), la Fiscalía General del Estado (FGE) y el Consejo General del Poder Judicial (CGPJ). Por regla general, en el debate público (político y mediático) suelen emplearse indistintamente unos y otros, sin reparar en que la información aportada por cada una de estas instancias está midiendo, en realidad, cosas distintas.

Si se analiza la figura 1, aunque todas las instituciones están haciendo referencia a su actuación en relación con la delincuencia cometida por los menores de edad penal, las cifras no coinciden y ello es porque cada una de ellas está midiendo en verdad algo diferente. Mientras los datos del Ministerio de Interior hacen referencia al número de menores de edad penal que han sido detenidos por las Fuerzas y Cuerpos de Seguridad del Estado (FCSE), los datos de la FGE hacen referencia al número de diligencias que esta institución abre cada año, cuando tiene conocimiento de que un menor de edad está implicado en una infracción penal como autor. Por su parte, los datos del CGPJ hacen referencia al número de expedientes de reforma que son finalmente incoados, una vez que el Ministerio Fiscal ha hecho uso del principio de oportunidad.

Además de referirse a cuestiones distintas hay también razones metodológicas que explican las diferencias. En efecto, el modo de recogida de cada una de estas fuentes de información es distinto en cada instancia; mientras los datos del MIR se obtienen de un formulario que es rellenado para cada detenido, los datos de la FGE consisten en una suma de las actuaciones que realizan anualmente en relación con los menores infractores. Por su parte los datos del CGPJ hacen referencia al número de expedientes de reforma (que son expedientes por hecho y no por sujeto) que son incoados cada año. Así, si se observa la figura, el número de diligencias incoadas en la Fiscalía supera con creces el número de detenidos y de expedientes de reforma ya que muchas de estas diligencias no hacen referencia a un nuevo delito registrado sino que recogen el resultado de la actuación que la Fiscalía realizado con alguna de las diligencias ya incoadas ${ }^{4}$.

\footnotetext{
${ }^{4}$ Cómo ya hemos puesto de manifiesto en otras ocasiones, la LORPM otorgó al Ministerio público, definitivamente y con los recursos necesarios, el impulso y la instrucción del procedimiento de reforma de menores. Para ello, en el año 2001 se crearon las Secciones Únicas en cada Fiscalía, que cuentan con personal y medios propios. Este hecho significa que, por vez primera en la justicia de menores, la Fiscalía se convierte en el principal referente, para todos
}

Revista Española de Investigación Criminológica 


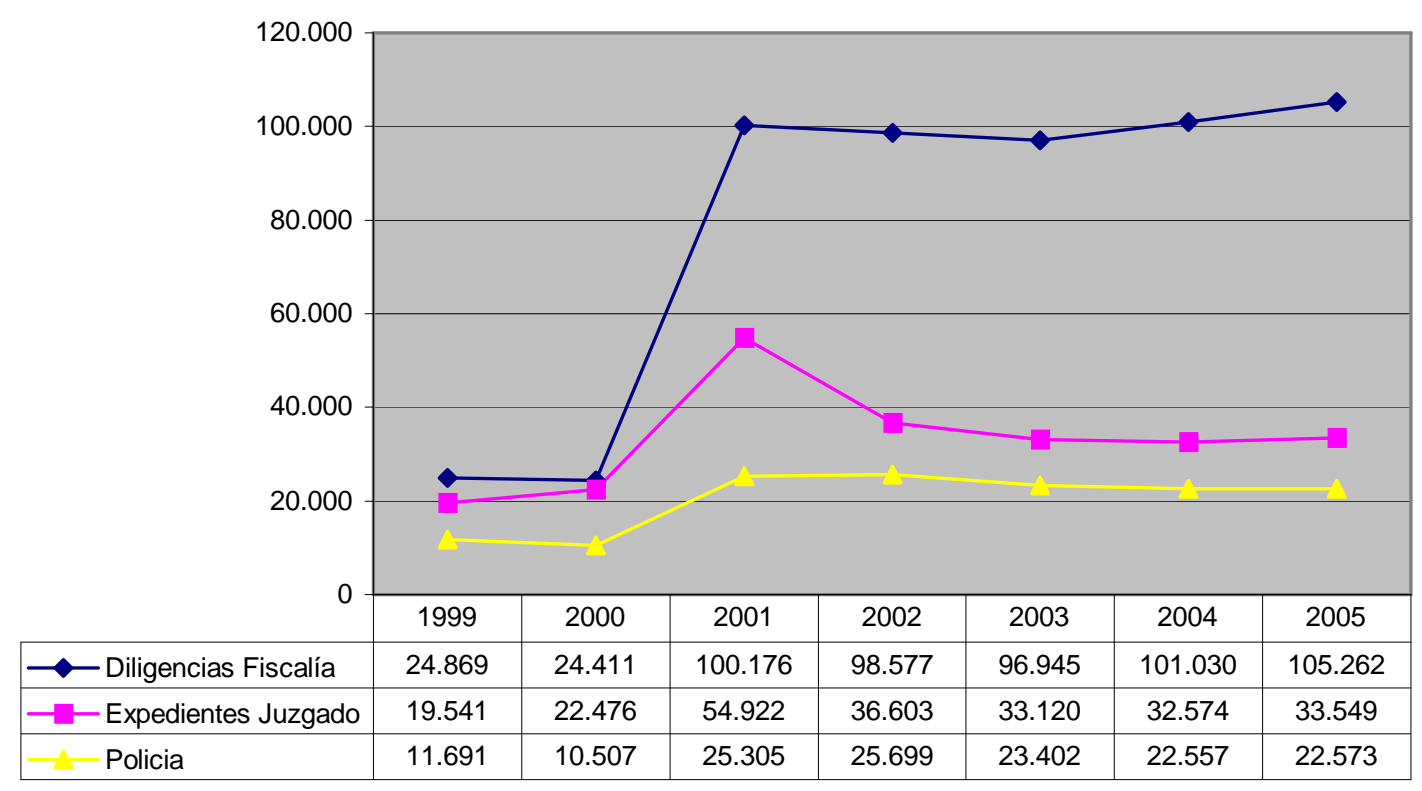

Figura 1. Datos oficiales sobre delincuencia juvenil 1999-2005. Fuente: FGE, CGPJ y MIR.

(1) Los datos de la Policía se refieren a las detenciones de menores de 12 a 16 años para el período 1999 y 2000 y detenciones de menores de 14 a 18 para el período (2001-2005)

A la vista de la Figura 1. es evidente concluir que cada institución está midiendo algo diferente y no sólo delincuencia juvenil, por lo tanto hay que ser muy consciente en cada momento de la fuente de la que procede la información con la que se trabaja, qué información aporta realmente y cuál elude, así como sus correspondientes limitaciones y sesgos.

A pesar de las diferencias numéricas que hay entre las distintas mediciones, es interesante comprobar que al menos en el caso de los datos del CGPJ y del MIR las tendencias coinciden. Ello indudablemente sirve para considerar la fiabilidad de estos datos y reafirmar la validez de estas fuentes como instrumentos de medida fiables, al menos para realizar análisis de tendencias generales. En ambos casos, en el año 2001, año de entrada en vigor de la LORPM que modificó los márgenes de edad penal, las

aquellos que estén en contacto con menores y/o tengan conocimiento de un hecho delictivo cometido por menores de edad. Este dato ha sido decisivo en la actuación de esta institución dentro del proceso de menores y ello se ha materializado en un aumento considerable del número de diligencias incoadas. Dicho aumento no implica en ningún caso un ascenso de la delincuencia juvenil sino más bien un cambio en el modo de proceder dentro de la propia jurisdicción (ver más extensamente en Rechea y Fernández Molina, 2006 y, en especial en, Fernández Molina, en prensa).

Revista Española de Investigación Criminológica

Artículo 4, Número 4 (2006) $\quad$ www.criminología.net

ISSN: 1696-9219 
cifras aumentaron más del doble ${ }^{5}$ y desde ese momento han permanecido estables durante estos últimos cinco años.

En el caso de los datos procedentes de la FGE muestran una tendencia al alza que lejos de constatar un aumento de la delincuencia juvenil, evidencian una mayor judicialización de los conflictos entre menores y una mayor carga de trabajo burocrático de esta instancia ${ }^{6}$.

Por lo tanto, no existe ninguna evidencia empírica que pueda amparar el temido aumento de la delincuencia juvenil al que se alude cada vez que se quiere justificar una reforma. Ni siquiera puede alegarse lo que sí ocurre en la mayoría de los países occidentales, un aumento de los delitos violentos (Barberet, 2001); ya que desde que estos comenzaron a aumentar desde 1997 (Rechea y Fernández Molina, 2006) en el último lustro las cifras, tal y como muestra la figura 2 , o se han estabilizado o descienden ${ }^{7}$.

\footnotetext{
${ }^{5}$ Un análisis más exhaustivo del efecto que produjo la entrada en vigor de la LORPM puede consultarse en Fernández Molina (en prensa).

${ }^{6}$ El número de diligencias archivadas es altísimo, tanto que el número de diligencias preliminares sobre las que el Fiscal toma algún tipo de decisión (incoación o desistimiento) no llega al 50\% del total (ver más extensamente en Fernández Molina, en prensa).

${ }^{7}$ Puede resultar alarmante el aumento del número de homicidios si se analiza en cifras absolutas; sin embargo, este dato sigue siendo insignificante y evidentemente excepcional en nuestra sociedad, moviéndose siempre entre unos porcentajes ínfimos.
}

Revista Española de Investigación Criminológica

Artículo 4, Número 4 (2006) $\quad$ www.criminología.net

ISSN: $1696-9219$ 


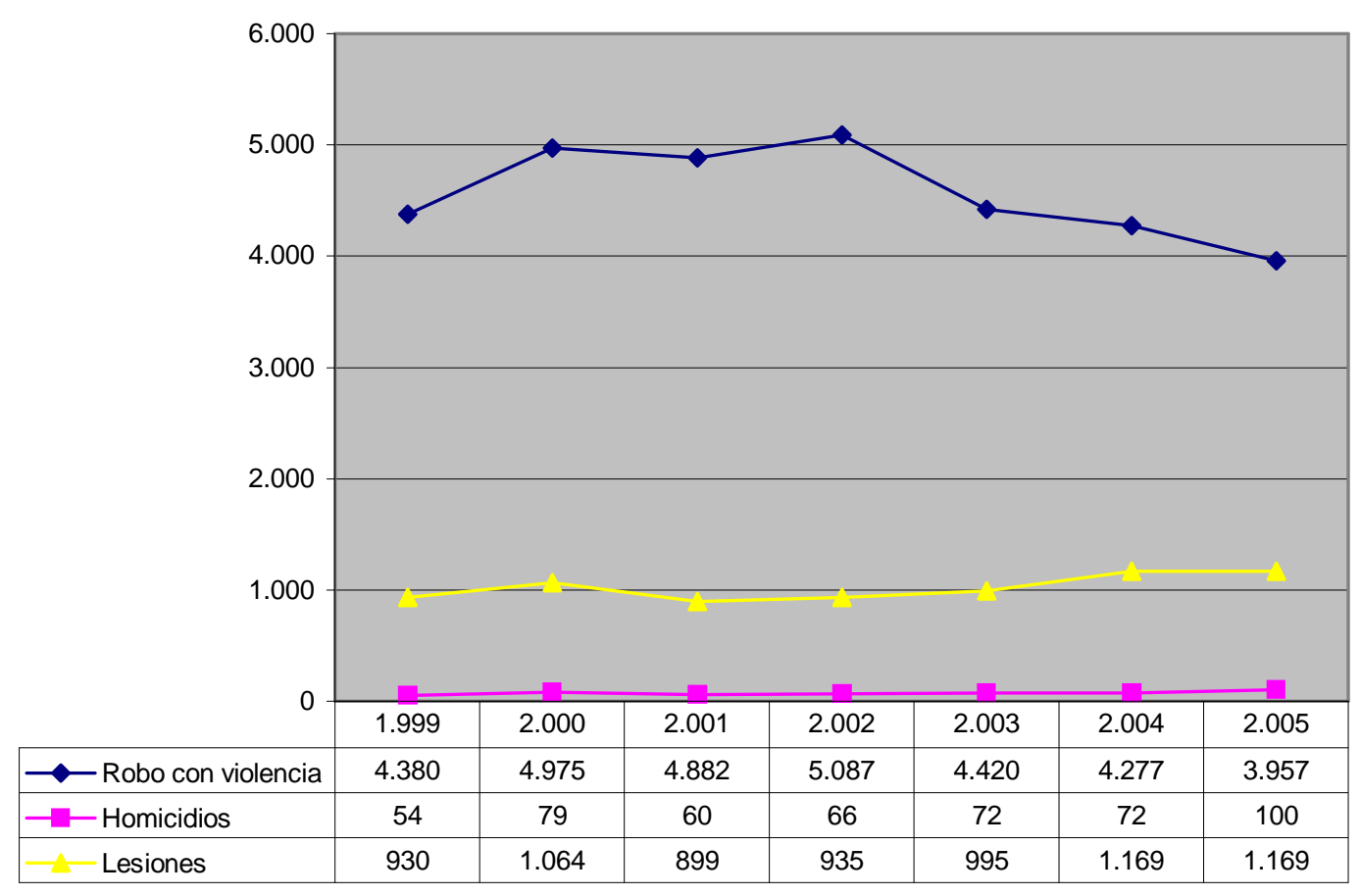

Figura 2. Número de detenidos (0-17 años) por delitos violentos (1999-2005). Fuente: MIR.

Llegados a este punto convendría concluir que podría realizarse un análisis sobre el volumen de delincuencia juvenil más completo, si contáramos con otros datos no oficiales procedentes de estudios de autoinforme. Sin embargo, el único estudio de autoinforme realizado en este país es del año 1992 (Barberet, Rechea y Montañes, 1994), lo cuál hace imposible llegar a alguna conclusión al respecto.

\section{Especialidades del sistema de justicia de menores}

A continuación se hará un breve repaso de los principales elementos del sistema de justicia de menores español, comprobando cuáles son las claves de este sistema y sus especialidades respecto al sistema penal de adultos. En un primer momento se hará un recorrido exponiendo la actuación de los distintos agentes involucrados en la detención, enjuiciamiento e intervención con los menores infractores. Posteriormente, se revisarán brevemente los requisitos y los plazos especiales que el sistema prevé para la detención preventiva de los jóvenes y menores delincuentes. Se analizarán las últimas propuestas de incorporación de la víctima al proceso de menores y se acabará realizando un repaso de las dos principales líneas programáticas sobre las que se asienta el sistema y sobre las que se intenta dar una respuesta equilibrada entre la necesidad de castigo y el que éste tenga un contenido eminentemente educativo. 


\subsection{Los agentes del sistema}

El sistema de justicia juvenil español está conformado por un grupo de profesionales que proceden de ámbitos distintos de trabajo. Tal y como exige la normativa de Naciones Unidas todos ellos deben poseer una adecuada especialización en materia de menores, con el objetivo final de garantizar que todas las actuaciones se adopten teniendo en cuenta el "superior interés del menor".

Aunque es el Fiscal, especialmente desde 2001, el que lidera el proceso de menores, todos los profesionales juegan un papel decisivo en el mismo y todas las actuaciones son igualmente importantes. Esto es, todos están a un mismo nivel en la actuación llevada a cabo en el sistema de justicia de menores, lo cual corrobora una tendencia que se ha manifestado en muchos países de nuestro entorno, que ha ido consolidando un sistema de justicia de menores horizontal que tradicionalmente poseía una estructura piramidal (Bailleau y Cartuyvels, 2002). A continuación se va a detallar brevemente el papel que juega cada uno de estos agentes en el sistema.

\subsection{1. $\quad$ El Fiscal de menores}

Como se decía anteriormente el Fiscal de menores es una pieza fundamental en el sistema de justicia de menores. Este papel principal fue introducido por vez primera en España a través de la reforma del año 1992, provocando en su momento una auténtica revolución, tanto porque este hecho suponía marcar una clara diferencia con lo que sucedía en el proceso penal ordinario, como por lo sorprendente de la decisión. Ni la tradición jurídica española, ni la preparación que desde las instancias gubernamentales se hizo para acometer esta decisión, hacían prever que el legislador iba apostar por tan 'inesperada' opción.

A través de esta decisión se incorporaba al sistema de justicia de menores español la figura del Fiscal instructor propia del sistema anglosajón, que otros países con una tradición jurídica muy similar a la nuestra ya habían incorporado a sus sistemas, es el caso de Alemania (Rössner, 1999), Austria (Jesionek, 1999) o Italia (Gatti, 1999). Esta decisión suponía la incorporación de un elemento extraño en el sistema judicial español que por supuesto no estuvo exento de críticas (Fernández Molina y Rechea, 2005). 
Sin embargo, y a pesar de los recelos, la experiencia demostró que la opción planteada no fue tan descabellada. La buena actuación llevada a cabo por estos profesionales en el sistema de justicia de menores español (Rechea y Fernández Molina, 2003) acabó consolidando la figura del Fiscal de menores instructor.

Por ello, y como no podía ser de otra manera, la Ley de 2000 consagró definitivamente a estos profesionales renovando la confianza que en su día depositó en ellos. La LORPM considera que la posición del Fiscal es especialmente relevante en este procedimiento en su doble condición de institución que constitucionalmente tiene encomendada la función de promover la acción de la Justicia y la defensa de la legalidad, así como de los derechos de los menores velando por el interés de estos ${ }^{8}$.

En concreto la Ley establece que corresponde al Fiscal la instrucción del procedimiento (art. 16). Para desarrollar su misión éste se va a auxiliar de la Policía judicial, a la que va a ordenar practicar las actuaciones necesarias para la comprobación de los hechos y de la participación del menor en los mismos (art. 6), y del Equipo técnico que le ayudará a determinar cuál es la medida más adecuada a la situación psicosocial del menor (art. 27.1).

Junto con la investigación de los hechos, la LORPM le atribuye también la función de impulsar el procedimiento, lo cual supone que va a intervenir además en todas las fases del procedimiento: en la fase de audiencia (artículos 8, 31 y 31), en las medidas cautelares (artículo 28), en la redacción de la sentencia, por el juego del principio acusatorio del artículo 8, en la ejecución de la medida (artículo 14, 44b y 50), en su sustitución o suspensión (artículos 40 y 51) y en el régimen de recursos (artículo 43).

Que duda cabe que este mayor protagonismo que ha ido adquiriendo el Fiscal en el proceso penal de menores ha oscurecido la actuación del Juez; hay quién habla de una pérdida de poder o de un desplazamiento de la figura del Juez frente a la del Fiscal (Schüler-Springorum, 1999). Sin embargo, creemos que más que un desplazamiento lo que se ha producido es un replanteamiento de las funciones del mismo. En el nuevo sistema penal de menores, el Juez desempeña labores de enjuiciamiento y de decisión en la fase final del procedimiento y labores de garante de la legalidad en la fase de investigación e instrucción de los hechos.

\footnotetext{
${ }^{8}$ Exposición de Motivos, apartado I, párrafo 9.
}

Revista Española de Investigación Criminológica

Artículo 4, Número 4 (2006) $\quad$ www.criminología.net

ISSN: $1696-9219$ 


\subsubsection{Fuerzas y Cuerpos de Seguridad del Estado: Grupos de Menores de la Brigada de Policía Judicial}

Aunque la LORPM reconoce la necesidad de unas Fuerzas y Cuerpos de Seguridad del Estado especializados, no les ha atribuido muchas competencias. En contra de lo que ocurre en otros países, en España la Policía Nacional, la Guardia Civil, las Policías Autónomas y las Locales no realizan con los menores actuaciones diferentes a las que realizan con los adultos. En países como Holanda, Reino Unido o Irlanda los Cuerpos de Policía tienen importantes funciones, especialmente, tienen competencia para amonestar a los menores o para adoptar decisiones de diversion.

En España los Grupos de menores del Cuerpo Nacional de Policía (GRUMES) y los de la Guardia Civil (EMUMES) sólo tienen atribuciones relativas a la persecución de los delincuentes menores de edad penal y de apoyo al Fiscal para el esclarecimiento de los hechos. La LORPM tan sólo se refiere a las Fuerzas y Cuerpos de Seguridad del Estado en dos ocasiones, cuando regula las funciones del Ministerio Fiscal y le encarga a éste ordenar a la Policía judicial que practique las actuaciones necesarias para la comprobación de los hechos y de la participación del menor en los mismos (artículo 6) y cuando regula el trámite de detención de los menores (artículo 17).

A parte de las funciones que les atribuye la LORPM también hay que tener en cuenta que los GRUMES y EMUMES por la inmediatez de su labor y por el potencial preventivo que tiene su actuación, se convierten en la práctica en un elemento determinante del sistema de justicia de menores, ya que estos Grupos están en contacto permanente con todas las instituciones: Juzgados de menores, Ministerio Fiscal, Servicios sociales, etc. Asimismo, en su actuación trabajan en colaboración con el resto de servicios policiales, como la policía de proximidad y otras unidades que actúen en la misma demarcación judicial. Por ello, y a pesar del silencio de la Ley en estos aspectos, la práctica policial se revela como una de las actuaciones más inmediatas y con mayor potencial preventivo de la delincuencia de menores.

La primera labor que estos Grupos tienen que realizar es la determinación de la edad, ya que va a ser la que determine el carácter de la intervención que debe adoptarse 
con el sujeto en concreto. Para la determinación de la edad podrán hacer uso de todos los medios de prueba admitidos en derecho (documentales, testificales, periciales).

Si comprobaran que el menor tiene menos de 14 años, y por lo tanto queda fuera del ámbito de actuación de la LORPM, su actuación policial deberá ceñirse al ámbito de la protección de los menores. En concreto, les será de aplicación las normas correspondientes de menores, tanto la de ámbito nacional, como la específica de cada Comunidad Autónoma; y deberá ponerse en conocimiento del Ministerio Fiscal, remitiéndole los hechos y circunstancias conocidas, con la correspondiente remisión del atestado policial, entregándose el menor a su representante legal o la entidad pública de protección de menores.

El resto de diligencias que la Policía pueda realizar tales como registros, declaraciones, reconocimientos, etc., se realizaran sólo cuando sea necesario, teniendo presente el carácter excepcional de cualquier diligencia que pueda resultar intimidante o estigmatizante para el menor. Y, en su caso, deberán realizarse siempre garantizando la protección del menor.

Sin embargo, la actuación donde la Policía tiene que ser más cautelosa en el respeto de los derechos del menor y donde debe de velar más por su protección, es en el caso de que el menor sea detenido (artículo 17 LORPM). La detención de un menor por funcionarios de policía no podrá durar más tiempo del estrictamente necesario para la realización de las averiguaciones tendentes al esclarecimiento de los hechos, y, en todo caso, dentro del plazo máximo de 24 horas, el menor detenido deberá ser puesto en libertad o a disposición del Ministerio Fiscal.

La detención deberá practicarse en la forma que menos perjudique al menor y garantizando la proporcionalidad de tal decisión con las circunstancias del menor y del delito cometido. Asimismo, será sujeto de todos los derechos que la CE y la LECrim regulan para cualquier detenido, y gozará de las garantías especiales que recogen la LORPM por ser menor de edad. Así, tal y como establece el artículo 17.2. "toda declaración del detenido, se llevará a cabo en presencia de su letrado", lo cual supone garantizar al menor los mismos derechos que al adulto. Sin embargo, y ahora si, en atención a su condición de menor edad, cualquier declaración que realice el menor deberá llevarse a cabo en presencia de aquellos que ejerzan la patria potestad, tutela o guarda del menor, -de hecho o de derecho, salvo que, en este último caso, las

Revista Española de Investigación Criminológica

Artículo 4, Número 4 (2006) $\quad$ www.criminología.net

ISSN: 1696-9219 
circunstancias aconsejen lo contrario. En cuyo caso la declaración se llevará a cabo en presencia del Ministerio Fiscal, representado por persona distinta del instructor del expediente.

Una última especialidad que se ha de tener en cuenta en relación con los menores detenidos es el lugar de custodia, que tal y como establece la LORPM, artículo 17.3. "Mientras dure la detención, los menores deberán hallarse custodiados en dependencias adecuadas y separadas de las que se utilicen para los mayores de edad, y recibirán los cuidados, protección y asistencia social, psicológica, médica y física que requieran, habida cuenta de su edad, sexo y características individuales". En este sentido la mayoría de las Comisarías una vez entró en vigor la Ley acometieron la reforma o la habilitación de unas estancias especiales, separadas de las comunes, donde los menores permanecen detenidos.

\subsubsection{Equipo Técnico}

Una de las principales funciones del Equipo Técnico (ET) es prestar asesoramiento técnico al Fiscal valorando el interés del menor. La LORPM no define en ningún momento qué es el interés del menor, pero si cuenta con que en el procedimiento se vaya a realizar una valoración técnica del mismo. Para ello dice cómo hay que valorarlo, con criterios técnicos y no formalistas, y quién debe hacerlo, equipos de profesionales especializados en el ámbito de las ciencias no jurídicas (Fernández Molina, 2002).

Esa valoración se lleva a cabo, a petición del Ministerio Fiscal, por un Equipo interdisciplinar formado por psicólogos, educadores y trabajadores sociales especialistas en menores, que van a analizar la situación personal, psicológica, familiar, educativa y social que rodean al menor y que van a plasmar en un informe (artículo 27).

Este informe que se elabora en la fase de instrucción, será determinante en las actuaciones que se sigan en el curso del proceso. Así, si el Equipo Técnico lo estima conveniente y en interés del menor puede proponer una intervención socio-educativa sobre el menor (art. 27.2) o una actividad reparadora o de conciliación con la víctima (art. 27.3). También puede proponer la conveniencia de no continuar el expediente en interés del menor, por haber sido expresado suficientemente el reproche al mismo a través de los trámites ya practicados, o por considerar inadecuada para el interés del

Revista Española de Investigación Criminológica

Artículo 4, Número 4 (2006) $\quad$ www.criminología.net

ISSN: $1696-9219$ 
menor cualquier intervención, dado el tiempo transcurrido desde la comisión de los hechos (art. 27.4). Asimismo, si el Fiscal decide continuar con el expediente este informe será uno de los aspectos que deberán ser valorados para la elección de la medida o medidas adecuadas, tanto por el Ministerio Fiscal y el letrado del menor en sus postulaciones, como por el Juez en su sentencia (art. 7.3).

No obstante su intervención como equipo asesor no se limita al momento inicial de la instrucción. La LORPM prevé también la intervención del Equipo técnico en otras fases del proceso, tratando de garantizar que todas las decisiones que se adopten en el procedimiento, se hagan valorando la situación psicosocial del menor.

Además se le han atribuido otras funciones al margen del asesoramiento técnico que son de gran relevancia para el proceso. Así, debe intervenir en las posibilidades de desjudicialización del expediente de los artículos 19.2., 19.3 y 27.4; y debe prestar asistencia social y psicológica al menor durante la detención del menor (artículo 17.3.).

\subsubsection{Juez de menores}

En el nuevo sistema que define la LORPM el Juez realiza múltiples funciones a lo largo de todo el procedimiento. Así, es Juez de garantías durante la instrucción; Juez sentenciador durante el enjuiciamiento de los hechos en la fase de audiencia y en la determinación de la sentencia; Juez de ejecución, durante la fase de ejecución de la medida en la que, al modo del Juez de vigilancia penitenciaria en adultos, debe garantizar que la Administración cumpla con lo adoptado en la sentencia y finalmente y será también Juez civil, al ser el responsable de tramitar la pieza separada de responsabilidad civil.

\subsubsection{Comunidades Autónomas}

Desde la reforma del año 1992, los servicios autonómicos son los encargados de ejecutar las medidas adoptadas por los Jueces de menores. El hecho de que el legislador concediera la competencia en la ejecución de las medidas judiciales a estos servicios tuvo una enorme trascendencia. Primero, porque ello suponía la descentralización del sistema de ejecución penal juvenil y segundo, porque con ello se apostaba por el diseño 
de una política global de infancia que abarcaría desde la protección de los menores en situación de riesgo hasta la respuesta judicial por el comportamiento delictivo.

Esta asunción de competencias originó, como ya sucediera en 1992, la necesidad de que las comunidades autónomas tuvieran que desarrollar en su propia legislación las previsiones que consideraron oportunas para la ejecución de las medidas previstas en la Ley. Con este motivo, algunas Comunidades Autónomas modificaron sus leyes, o incluso, aprobaron otras nuevas, teniendo en cuenta la nueva situación que generaba la LORPM. La tabla 1 que se muestra a continuación, refleja la nueva situación normativa de las Comunidades Autónomas.

Tabla 1. Leyes autonómicas sobre protección de menores vigentes

\begin{tabular}{|c|c|c|}
\hline CC.AA. & Número & Título \\
\hline Andalucía & $1 / 1998$ & Ley de los derechos y la atención del menor \\
\hline Aragón & $12 / 2001$ & Ley de la infancia y la adolescencia \\
\hline Asturias & $1 / 1995$ & Ley de protección de menores \\
\hline Baleares & $\begin{array}{l}6 / 1995 \\
7 / 1995\end{array}$ & $\begin{array}{l}\text { Ley de aplicación de las medidas judiciales } \\
\text { sobre menores infractores } \\
\text { Ley de protección de menores }\end{array}$ \\
\hline Canarias & $1 / 1997$ & Ley de atención integral a los menores \\
\hline Cantabria & $7 / 1999$ & $\begin{array}{l}\text { Ley de Cantabria de Protección de la Infancia y } \\
\text { Adolescencia }\end{array}$ \\
\hline Castilla-La Mancha & $3 / 1999$ & Ley del menor \\
\hline Castilla y León & $14 / 2002$ & $\begin{array}{l}\text { Ley de promoción, atención y protección a la } \\
\text { infancia }\end{array}$ \\
\hline Cataluña & $8 / 2002$ & $\begin{array}{l}\text { Ley de modificación de la Ley } 37 / 1991 \text {, de } 30 \\
\text { de diciembre, sobre medidas de protección de } \\
\text { los menores desamparados de la adopción y de } \\
\text { regulación de la atención especia a los } \\
\text { adolescentes con conductas de alto riesgo }\end{array}$ \\
\hline Extremadura & $4 / 1994$ & Ley de protección y atención a menores \\
\hline Galicia & $3 / 1997$ & $\begin{array}{l}\text { Ley de protección jurídica, económica y social } \\
\text { de la familia, la infancia y la adolescencia }\end{array}$ \\
\hline La Rioja & $4 / 1998$ & Ley del menor \\
\hline Madrid & $6 / 1995$ & $\begin{array}{l}\text { Ley de garantías de los derechos de la infancia } \\
\text { y de la adolescencia }\end{array}$ \\
\hline Murcia & $3 / 1995$ & Ley de la infancia \\
\hline Valencia & $7 / 1994$ & Ley de la infancia \\
\hline Ceuta y Melilla & \multicolumn{2}{|c|}{$\begin{array}{l}\text { Al no tener capacidad legislativa, se rigen por la LO } \\
1 / 1996 \text { de protección jurídica del menor. }\end{array}$} \\
\hline
\end{tabular}

Fuente: elaboración propia a través de consulta realizada al Ministerio de Trabajo y Asuntos Sociales 


\subsubsection{Abogado defensor}

Con la intención de garantizar el cumplimiento de los derechos y garantías jurídicas de los menores la LORPM prestó especial atención a la participación del letrado. Así, tal y como indica su Exposición de motivos 'El letrado del menor tiene participación en todas y cada una de las fases del proceso, conociendo en todo momento el contenido del expediente, pudiendo proponer pruebas e interviniendo en todos los actos que se refieren a la valoración del interés del menor y a la ejecución de la medida, de la que puede solicitar la modificación"9. Su participación comienza desde el momento en que se incoa el expediente (art. 22) e incluso antes, si el menor es detenido por las FCSE y tiene que representarle cuando le tomen declaración.

\subsection{Medidas cautelares}

Uno de los aspectos más conflictivos durante la instrucción del proceso de menores es la necesidad de adoptar o no una medida cautelar. Una vez que la Policía ha puesto a disposición del Fiscal al menor, éste tiene 24 horas para tomar una decisión y valorar si lo pone en libertad para tomarle declaración posteriormente o si lo pone en conocimiento del Juez para que adopte alguna medida cautelar (art. 28). En ese caso, el Juez dispone de 24 horas para adoptar una medida. En esa decisión el Juez debe valorar la seguridad y la protección del menor, la gravedad del delito, el historial delictivo del menor y la alarma social que haya suscitado el hecho.

La reforma que en estos momentos se debate en el Senado ha previsto la incorporación de un nuevo requisito: la valoración de la "debida protección de la víctima", esto es, la medida cautelar tiene como objetivo no sólo la custodia y la defensa del menor sino también la protección de la víctima ${ }^{10}$. Con esta finalidad ha incluido también una nueva medida cautelar, la prohibición de aproximarse o comunicarse con la víctima o con aquellos de sus familiares u otras personas que determine el Juez. Esta medida junto con las ya previstas anteriormente, el internamiento, la libertad vigilada o la convivencia con grupo educativo o familiar, son todas las opciones con las que cuenta el Juez para controlar preventivamente al menor antes de celebrase el juicio.

\footnotetext{
${ }^{9}$ Exposición de Motivos Apartado II, párrafo 9.

${ }^{10}$ Sobre esta nueva protección de la víctima se hablará más adelante.
}

Revista Española de Investigación Criminológica 
El plazo que tiene el Juez con la LORPM para imponer la medida de internamiento es no superior a 3 meses prorrogables a otros 3. Dicho plazo, sin embargo, ha sido cuestionado también en el proceso de tramitación de la reforma y se prevé que el tiempo máximo sea de 6 meses prorrogables a otros 3. Con ello se haría efectiva una demanda que desde hacía ya mucho tiempo Jueces y Fiscales y también responsables de entidades públicas habían hecho pública, al considerar que para algunos casos especialmente complejos el plazo previsto por la LORPM parecía insuficiente ${ }^{11}$.

\subsection{Desjudicialización}

Una de las principales líneas de actuación dentro del proceso de menores es la desjudicialización, esto es, la posibilidad de que el menor a pesar de haber sido detenido por la comisión de un hecho delictivo pueda ver su expediente archivado sin más o bajo la condición de realizar alguna tarea conciliadora, reparadora o educativa.

El hecho de que sea el Fiscal quién tiene el monopolio de la acción penal en el sistema de justicia juvenil español supone, entre otras cosas, que en sus manos está la importante labor de fomentar las estrategias desjudicializadoras del expediente, cuyo alcance se va analizar a continuación. Hay dos momentos en los que la LORPM permite archivar el expediente en interés del menor evitando la respuesta formal: el expediente puede ser archivado por el Fiscal en sede de Fiscalía o por el Juez nada más incoar el procedimiento para evitar que se produzca el juicio.

\subsubsection{Desjudicialización realizada por el Fiscal de menores}

La LORPM da al Fiscal mayor discrecionalidad que la que tenía con el sistema del año 1992. Con el sistema anterior el Fiscal debía solicitar al Juez el archivo del expediente en interés del menor; con la nueva ley si el menor ha cometido un delito menos grave sin violencia o intimidación o una falta y no es reincidente, el Fiscal puede archivar el expediente sin tener que comunicarlo al Juez (artículo 18). De esta forma el Fiscal realiza una importante labor de filtro de entrada al sistema de justicia de menores,

${ }^{11}$ Ver Conclusiones de la reunión de Jueces y Fiscales de menores del mes de noviembre de 2003 a la que también asistieron numerosos responsables de entidades públicas.

Revista Española de Investigación Criminológica

Artículo 4, Número 4 (2006) $\quad$ www.criminología.net

ISSN: $1696-9219$ 
ya que puede dejar fuera a los delincuentes primarios que cometen delitos de escasa gravedad.

\subsubsection{Desjudicialización realizada por el Juez de menores}

El Juez puede archivar el expediente si el menor ha realizado algún tipo de actividad que queda bajo el paraguas de la filosofía restauradora, esto es, si se ha producido una conciliación con la víctima, si ha reparado el daño causado o si ha realizado determinadas tareas educativas propuestas por el ET. También puede archivar el expediente, a pesar de que el menor no sea un delincuente primario: si ha cometido un delito de escasa gravedad, especialmente si no ha habido violencia e intimidación, y el ET aconseja que en interés del menor es aconsejable dar una segunda oportunidad; o cuando se estima que los trámites llevados a cabo han sido suficientes para responsabilizar al menor por sus actos o porque el tiempo trascurrido desde la comisión de los hechos hace innecesario o contraproducente cualquier tipo de intervención.

\subsection{3. $\quad$ Aplicación práctica de la desjudicialización en el sistema de justicia} de menores español.

La figura 3 muestra el resultado de la aplicación de estas estrategias desjudicializadoras en el sistema de justicia de menores español durante los últimos cinco años. 


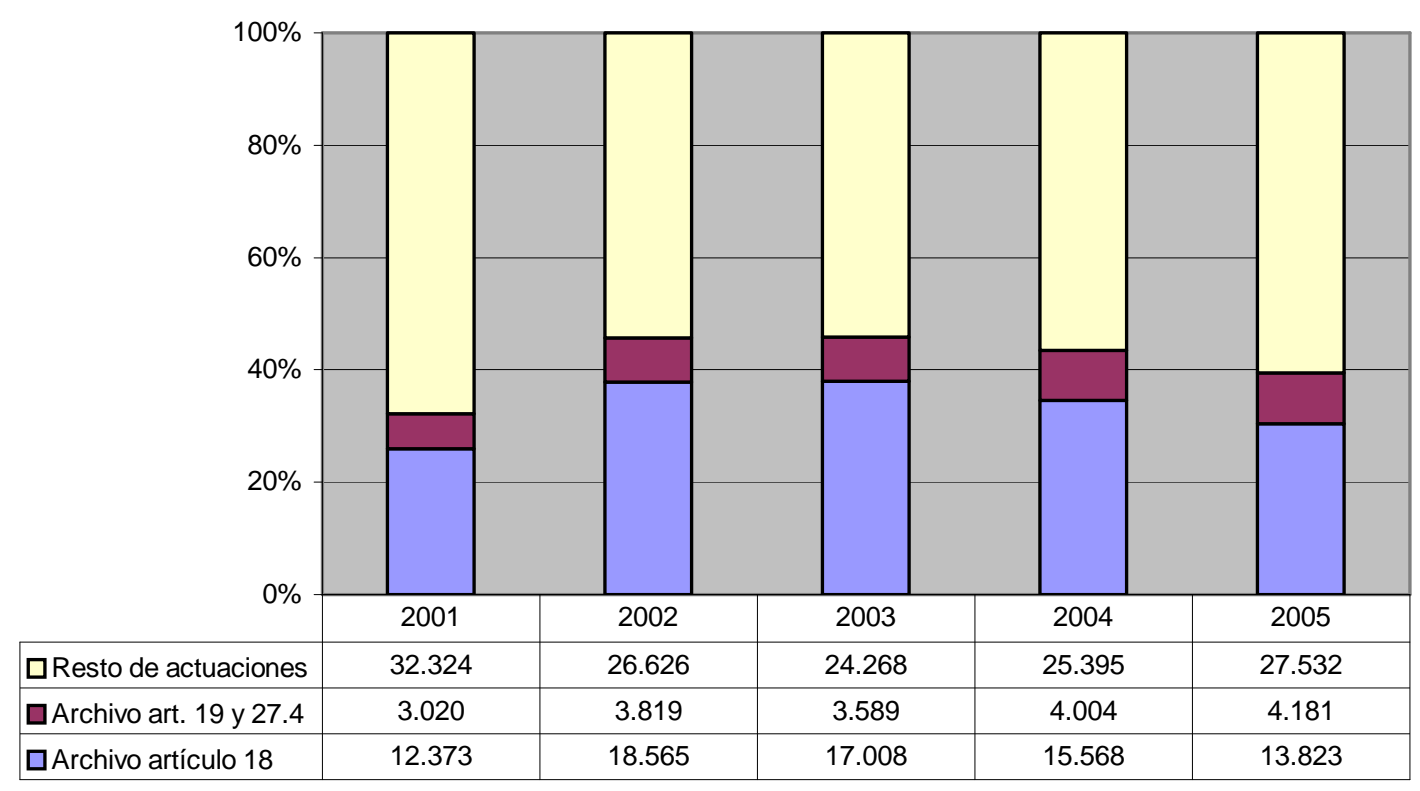

Figura 3. Implementación de las estrategias desjudicializadoras en España ${ }^{12}$ (2001-2005). Fuente: MFGE

Los datos de la figura reflejan un balance de la utilización de las estrategias desjudicializadoras aceptable. No obstante, y al contrario de lo que parecía en los primeros años de aplicación de la Ley (Fernández Molina y Rechea, 2006), con una tendencia al alza en su empleo, el resultado de la aplicación de los dos últimos años ha invertido la tendencia, si bien es cierto que todavía mantiene casi un $40 \%$ de los casos fuera del sistema de justicia de menores.

Sí que se mantiene la primacía de la desjudicialización realizada en sede de Fiscalía a través del desistimiento del artículo 18 respecto a la que realiza el Juez a través de los sobreseimientos de los artículos 19 y 27.4. Lo cual revela que, en efecto, los Fiscales realizan una labor de filtro de entrada al sistema muy importante. Sin embargo, la tendencia es que los Fiscales cada vez filtren menos asuntos, mientras que los Jueces sobreseen un porcentaje de casos similar e incluso cada vez más numeroso ${ }^{13}$.

No obstante, este balance nacional presenta en cada Comunidad Autónoma, e incluso en cada provincia, unos matices muy particulares. Así, hemos podido contrastar

${ }^{12}$ En esta figura no se ha tenido en cuenta el número de expedientes preliminares incoados en Fiscalía que finalmente han sido archivados ya fuera porque han pasado un filtro de legalidad (no se ha podido demostrar que ha habido delito o quién es el autor) o porque son expedientes que hacen referencia a alguna actuación relativa a otros expedientes (inhibiciones, acumulaciones).

13 Los archivos por sobreseimiento de los artículos 19 y 27.4. han ido aumentando progresivamente: $6,3 \%$ en $2001,7,8 \%$ en $2002,7,9 \%$ en $2003,8,9 \%$ en 2004 y $9,2 \%$ en 2005 .

Revista Española de Investigación Criminológica

Artículo 4, Número 4 (2006) $\quad$ www.criminología.net

ISSN: 1696-9219 
en otras ocasiones que no todos los Fiscales hacen el mismo uso de su capacidad desjudicializadora y que el empleo del desistimiento del artículo 18 es muy desigual en el territorio español (Fernández Molina y Rechea, 2005). Del mismo modo, y generalmente de manera inversamente proporcional no en todas las jurisdicciones se hace un uso parecido de las otras dos posibilidades de desjudicialización, especialmente, las relacionadas con las prácticas que obedecen a la filosofía restauradora ${ }^{14}$.

Por otra parte, el sistema a través de las estrategias desjudicializadoras no solo evita la respuesta formal sino que también permite proporcionar una respuesta rápida a la pequeña delincuencia. Si se observa la tabla 2 se puede comprobar el tiempo que transcurre desde la comisión del delito y desde que se inicia el procedimiento hasta que el expediente es archivado en interés del menor (art. 27.4), o hasta que se lleva a cabo un proceso restaurador o el tiempo que transcurre hasta que se le impone una medida judicial.

Tabla 2. Tiempo transcurrido entre los diferentes momentos del proceso (media y mediana)

\begin{tabular}{|l|c|c|}
\hline & Media & Mediana \\
\hline Archivo en interés del menor & & 17,8 meses \\
Desde comisión delito & 20,2 meses & 3,4 meses \\
Desde inicio del procedimiento & 4,6 meses & \\
\hline Archivo por proceso restaurador & & 6,3 meses \\
Desde comisión delito & 8,1 meses & 5 meses \\
Desde inicio del procedimiento & 5,6 meses & \\
\hline Adopción de medida & & 11,1 meses \\
Desde comisión delito & 13,8 meses & 8,6 meses \\
Desde inicio del procedimiento & 9,3 meses & \\
\hline
\end{tabular}

Fuente: Fernández Molina (2004).

En concreto es el archivo por interés del menor el que tarda menos tiempo en tramitarse: 4,6 meses, frente a los 5,6 meses que tarda el procedimiento cuando se lleva a cabo una conciliación, reparación o tareas socioeducativas y a los 9,3 meses cuando el resultado supone la adopción de una medida educativa. Sin embargo, son los expedientes archivados en interés del menor, los que tardan más tiempo en resolverse desde la comisión de los hechos: 20,2 meses. Si bien es el dato de la mediana el que

${ }^{14}$ Es el caso de la comunidad autónoma de Castilla-La Mancha que al menos en los tres primeros años de aplicación de la LORPM evidenció una peculiar tendencia en el modo de entender y aplicar las estrategias desjudicializadoras (Fernández Molina y Rechea, 2006).

Revista Española de Investigación Criminológica

Artículo 4, Número 4 (2006) $\quad$ www.criminología.net

ISSN: $1696-9219$ 
resulta más determinante, ya que la mitad de los expedientes archivados por este motivo tardaron en resolverse desde la comisión del delito 17,8 meses. Este dato vendría a decir que de los dos motivos por los que el Equipo técnico puede solicitar el archivo en interés del menor, tal y como establece el artículo 27.4, la razón mayoritaria es la de considerar inadecuado para el interés del menor cualquier tipo de intervención dado el tiempo transcurrido desde la comisión de los hechos.

\subsection{La víctima en el proceso de menores}

Si hay un dato que caracteriza la política-criminal actual es la de la gran revitalización que ha sufrido la figura de la víctima. Fruto de los desarrollos de la Victimología y de la Restorative Justice (Justicia Restauradora) las víctimas han pasado de su tradicional posición, neutralizada por un sistema que se centraba exclusivamente en la respuesta otorgada al delincuente, a una posición privilegiada en el ámbito de la decisión legislativa que la ha convertido en un agente social principal a la hora de incentivar y poner en marcha las reformas legales ${ }^{15}$.

En este sentido, puede resultar muy interesante comprobar la evolución que ha sufrido al respecto la legislación penal juvenil de nuestro país. En un primer momento el Proyecto de Ley de 1998 previó incorporar a la víctima al sistema a través de dos estrategias: perfeccionando el procedimiento de conciliación y reparación que la LORJM había posibilitado y arbitrando un procedimiento, que iba a permitir satisfacer los daños y perjuicios que la víctima o el perjudicado por el delito pudieran haber sufrido, a través de la apertura de una pieza separada donde se ventilaría la responsabilidad civil. Excluyendo de modo tajante el ejercicio de la acusación particular. Posteriormente, y tras la reforma que sufrió la Ley en su paso por el Senado, este aspecto se modificó y se incorporó la figura de un coadyuvante del Fiscal para los casos de delitos violentos cometidos por jóvenes de 16 y 17 años. Finalmente, y tras el impacto mediático y la consecuente alarma social que provocó el caso Sandra Palo, el sistema permite definitivamente la acusación particular, tras la reforma que sufrió la Ley a través de la LO 15/2003, de 25 de noviembre, de reforma del Código Penal.

\footnotetext{
${ }^{15}$ Un análisis más detallado de la posición de la víctima en el sistema de justicia de menores puede consultarse en Fernández Molina (en prensa).
}

Revista Española de Investigación Criminológica 
De este modo lo que empezó siendo un sistema que obviaba totalmente la situación y la asistencia de las víctimas pasó a ser un sistema que, a pesar de los riesgos que supone incorporar el ánimo vindicativo a un sistema eminentemente educativo, apostó por atender estos intereses. Sin embargo, la valoración de su incorporación no ha resultado muy positiva y ha evidenciado que, efectivamente, el carácter simbólico que latía detrás de todas estas reformas ha llegado a provocar más indefensión para las propias víctimas que otra cosa, y por supuesto, ha pervertido el proceso educativo que pretende llevarse a cabo con los menores infractores (Fernández Molina y Rechea, 2006).

Quizás sea esta indefensión la que explique el que de nuevo la reforma que se está debatiendo actualmente, vuelva a incidir en la necesidad de mayor atención y reconocimiento de los derechos de las víctimas y los perjudicados. Brevemente, el Proyecto prevé modificaciones legislativas para que la víctima se encuentre informada en todo momento del desarrollo del expediente. De manera inmediata se les instruirá de las medidas de asistencia a las víctimas que prevé el nuevo texto, así tendrán derecho igual que ocurre en el proceso de adultos de personarse y ser parte en el proceso ${ }^{16}$, para lo cual y como novedad de este texto, el Secretario Judicial tiene la obligación de instruirles en estos derechos.

Asimismo, y como se decía en relación con las medidas cautelares, se prevé la posibilidad de que el Juez pueda adoptar decisiones que protejan si fuera necesario a la víctima pudiendo adoptar medidas de alejamiento como medidas cautelares. Esta misma medida también se ha incorporado como posible judicial y aparece recogida en el nuevo catálogo del artículo 7, en concreto el Proyecto prevé: "la prohibición de aproximarse o comunicarse con la víctima o con aquellos de sus familiares u otras personas que determine el Juez. Esta medida impedirá al menor acercarse a ellos, en cualquier lugar donde se encuentren, así como a su domicilio, a su centro docente, a sus lugares de trabajo y a cualquier otro que sea frecuentado por ellos. La prohibición de comunicarse con la víctima, o con aquellos de sus familiares u otras personas que determine el Juez o Tribunal, impedirá al menor establecer con ellas, por cualquier medio de comunicación o medio informático o telemático, contacto escrito, verbal o visual".

${ }^{16}$ El nuevo artículo 4 regula de manera extensa los derechos de las víctimas y de los perjudicados.

Revista Española de Investigación Criminológica

Artículo 4, Número 4 (2006) $\quad$ www.criminología.net

ISSN: $1696-9219$ 
Finalmente, también se ha previsto la modificación de la pieza de responsabilidad civil, que se tramitará conjunta y simultáneamente con el expediente principal, simplificando el farragoso procedimiento que había establecido la LORPM en inicio y remitiendo a las reglas generales del proceso civil para la tramitación de la misma. Asimismo, se hace referencia expresa a la necesidad de que el proceso se realice en determinadas condiciones para preservar la intimidad del menor.

\subsection{El enjuiciamiento de menores infractores}

Una vez el Fiscal decide no archivar el caso, el proceso continua y da comienzo el proceso formal, finalizando la instrucción y dando paso a la fase en la que tiene lugar la audiencia. En ese momento el Juez debe oír a cada una de las partes, incluido el menor y debe tomar una decisión que deberá motivar debidamente en la sentencia.

3.5.1. Reglas para la aplicación de las medidas judiciales previstas en la LORPM

El Juez no se encuentra obligado, tal y como sucede en la justicia de adultos, a imponer una medida determinada, según el hecho cometido, sino que tendrá que valorar de modo flexible no sólo la prueba y valoración jurídica de los hechos, sino especialmente la edad, las circunstancias familiares y sociales, la personalidad y el interés del menor (art. 7.3). No obstante, frente a este reconocimiento de una amplia discrecionalidad judicial, en algunas ocasiones, determinados aspectos como la edad, el tipo de delito cometido y su gravedad o el hecho de ser reincidente, van a jugar también un papel definitivo.

Así para garantizar que los hechos más leves no puedan ser castigados muy duramente, en el caso de que el menor haya cometido una falta el Juez de menores sólo podrá imponer las medidas de amonestación, permanencia de fin de semana hasta un máximo de cuatro fines de semana, prestaciones en beneficio de la comunidad hasta cincuenta horas, y privación del permiso de conducir o de otras licencias administrativas. 
En sentido contrario el artículo 9.4. establece que si el menor tuviese 16 años cumplidos en el momento de la comisión de los hechos y el delito se hubiera cometido con violencia o intimidación en las personas o con grave riesgo para la vida o integridad de las mismas, la medida puede durar un máximo de cinco años (los trabajos en beneficio de la comunidad y las permanencias de fin de semana podrán alcanzar doscientas horas y dieciséis fines de semana respectivamente) en vez del máximo de dos años que puede durar una medida con carácter general. No obstante, para decidir esta prolongación en la duración de la medida, el Equipo técnico deberá aconsejar en su informe la imposición de una medida de duración superior al máximo de tiempo previsto en la regla $3^{\text {a }}$. Por ello, a pesar de tener en cuenta la naturaleza del hecho, todavía se puede considerar que el 'interés del menor' es un elemento determinante para fundamentar la duración de la medida todavía en este supuesto el 'interés del menor' puede ser un elemento determinante para fundamentar la duración de la medida (Ornosa, 2003).

Sin embargo, esto no ocurre en el supuesto del artículo 9.5. ni en la redacción de la Disposición Adicional IV, cuando ante el mismo supuesto que el caso anterior (menor de entre 16 y 18 que comete un delito grave), se le sume el hecho de que el menor sea reincidente o que haya cometido un delito de terrorismo o un delito constitutivo de actos de favorecimiento, apoyo o reclamo de la actividad de bandas, organizaciones o grupos terroristas, o un delito de asesinato u homicidio doloso, o de agresión sexual. En ese caso el Juez obligatoriamente debe adoptar la medida de internamiento en centro cerrado sin que pueda modificarla o sustituirla durante el primer año de cumplimiento efectivo. Parece que en esta ocasión al sistema no le preocupa el interés del menor, ni le inquieta su evolución durante el primer año de internamiento, sino tan sólo quiere que se garantice su estancia en un centro cerrado.

En efecto, en estos casos se prescinde del principio de flexibilidad para establecer la imposición forzosa de una medida concreta, lo cual supone un quiebro importante de éste en la elección de la medida y en la individualización de la respuesta que pretende la LORPM, lo que puede producir serios efectos distorsionadores en la finalidad última de la actuación judicial. Y es que como hemos manifestado en otras ocasiones (Fernández Molina, 2002) con la LORPM y sus sucesivas reformas el Juez de menores tiene un marco de actuación más estrecho que con la Ley anterior, ya que 
ciertas decisiones impedirán la adopción de medidas, que, tal vez, desde la perspectiva del interés del menor, podrían ser positivas.

De otro lado, la larga duración de las medidas en estos casos es a todas luces excesiva. Por muy grave que haya sido el delito cometido y por muy deficientes y necesitadas de intervención que sean sus circunstancias personales, familiares, educativas o sociales, suponen una intervención prolongadísima en el tiempo, dada la diferente percepción del tiempo en los menores por su edad y su personalidad en evolución. Además, como muy acertadamente señala Ornosa (2003) si en un máximo de dos años no se ha logrado una intervención educativa, en más tiempo difícilmente se va a conseguir ${ }^{17}$. Parece pues evidente que, en relación con el denominado núcleo duro de la delincuencia juvenil (menores reincidentes o responsables de hechos graves) el sistema pretende ser especialmente exigente, adoptando soluciones de talante claramente punitivo y retributivo.

La siguiente tabla muestra, de un modo esquemático, todas las limitaciones que el Juez de menores debe tener en cuenta a la hora de adoptar una decisión.

${ }^{17}$ En este sentido la Criminología ha aportado información de sumo interés respecto a las cualidades de una 'intervención de éxito' con menores infractores. Así sabemos que educar a un delincuente juvenil que lleva años haciéndolo, requiere un esfuerzo planificado, intensivo y sistemático. La intervención en centro cerrado puede ser, en ocasiones, ciertamente importante, pero sin una labor provechosa de prevención secundaria en su entorno, muchos jóvenes antisociales seguirán en camino del crimen en su edad adulta. No basta con que los jóvenes mejoren en sus actitudes o comportamientos en el lugar de la intervención; se hace preciso que utilicen los nuevos aprendizajes en la vida diaria. La investigación presenta tres estrategias principales de intervención: 1) programas intensivos; 2) con una amplia capacidad de generalización y 3) coordinados con programas de apoyo y seguimiento en la comunidad (Garrido, 1995 y 2001).

Revista Española de Investigación Criminológica

Artículo 4, Número 4 (2006) $\quad$ www.criminología.net

ISSN: $1696-9219$ 
Tabla 3. Reglas especiales para la aplicación de medidas a menores infractores

\begin{tabular}{|c|c|c|c|}
\hline $\begin{array}{l}\text { Edad/ } \\
\text { Hecho }\end{array}$ & $\begin{array}{l}\text { Delitos en los que se haya } \\
\text { empleado violencia o } \\
\text { intimidación en las } \\
\text { personas o se haya } \\
\text { actuado con grave riesgo } \\
\text { para las mismas }\end{array}$ & $\begin{array}{l}\text { Delitos en los que se haya } \\
\text { empleado violencia o } \\
\text { intimidación en las } \\
\text { personas o se haya } \\
\text { actuado con grave riesgo } \\
\text { para las mismas y el } \\
\text { menor sea reincidente }\end{array}$ & $\begin{array}{l}\text { Asesinato, Homicidio, } \\
\text { Violación y Terrorismo }\end{array}$ \\
\hline $\begin{array}{c}14-15 \\
\text { años }\end{array}$ & & & $\begin{array}{l}\text { De } 1 \text { a } 4 \text { años en un } \\
\text { centro cerrado de } \\
\text { internamiento }+3 \text { años de } \\
\text { libertad vigilada (la } \\
\text { medida no puede ser } \\
\text { modificada hasta que no } \\
\text { haya transcurrido la } \\
\text { mitad de la duración de la } \\
\text { medida de internamiento } \\
\text { impuesta) }\end{array}$ \\
\hline $\begin{array}{c}16-17 \\
\text { años }\end{array}$ & $\begin{array}{l}\text { Las medidas pueden } \\
\text { alcanzar hasta } 5 \text { años. Si } \\
\text { fuera una P.S.B.C. podrá } \\
\text { alcanzar las } 200 \text { hs y } \\
\text { hasta } 16 \text { fines de semana } \\
\text { en la medida de } \\
\text { permanencia de fines de } \\
\text { semana }\end{array}$ & $\begin{array}{l}\text { De } 1 \text { a } 5 \text { años de } \\
\text { internamiento en régimen } \\
\text { cerrado+ } 5 \text { años de } \\
\text { libertad vigilada (la } \\
\text { medida no puede ser } \\
\text { modificada hasta que no } \\
\text { haya transcurrido el } \\
\text { primer año de duración } \\
\text { de la medida de } \\
\text { internamiento impuesta) }\end{array}$ & $\begin{array}{l}\text { De } 1 \text { a } 8 \text { años en un } \\
\text { centro cerrado de } \\
\text { internamiento }+5 \text { años de } \\
\text { libertad vigilada (la } \\
\text { medida no puede ser } \\
\text { modificada hasta que no } \\
\text { haya transcurrido la } \\
\text { mitad de la duración de la } \\
\text { medida de internamiento } \\
\text { impuesta) }\end{array}$ \\
\hline
\end{tabular}

Como se decía en el primer apartado el Proyecto que se debate actualmente en las Cámaras, prevé también cambios en las reglas de aplicación de las medidas que puede adoptar el Juez de menores. Nuevamente el legislador, como ya hiciera con la LORPM y sus sucesivas reformas, insiste en decidir en abstracto y de antemano la propuesta que se tiene que dar al menor, y va restringiendo el ámbito de discrecionalidad del Juez de menores, por mucho que lo niegue en su Exposición de Motivos. Así, de nuevo el núcleo duro de la delincuencia juvenil vuelve a ser el

${ }^{18}$ En el caso de que fuera un delito de terrorismo que en el Código penal de adultos lleve aparejada más de 15 años de prisión los límites se extienden de 1 a 5 años de internamiento en un centro cerrado +3 años de libertad vigilada si el menor tiene 14 o 15 años y de 1 a 10 años de internamiento en un centro cerrado +5 años de libertad vigilada si el menor tiene 16 o 17 años. Asimismo la medida no puede ser modificada hasta que no haya transcurrido la mitad de la duración de la medida de internamiento impuesta

Revista Española de Investigación Criminológica

Artículo 4, Número 4 (2006) $\quad$ www.criminología.net

ISSN: $1696-9219$ 
principal objeto de atención que plantea la reforma y el endurecimiento de la respuesta la solución para casi todos los problemas.

En primer lugar, se amplían los supuestos en los que se puede adoptar una medida de internamiento en régimen cerrado. Si con el texto vigente esta medida está reservada para cuando el menor haya cometido un delito en el que su comisión se ha empleado violencia o intimidación en las personas o actuado con grave riesgo para la vida o la integridad física de las mismas, la nueva reforma prevé que en adelante sea aplicable en estos tres supuestos:

- Cuando los hechos estén tipificados como delito grave

- Cuando los hechos estén tipificado como delito menos grave, pero en su ejecución se haya empleado violencia o intimidación en las personas o se haya generado grave riesgo para la vida o la integridad física

- Cuando los hechos tipificados como delito se cometan en grupo o el menor perteneciere o actuare al servicio de una banda, organización o asociación, incluso de carácter transitorio, que se dedicare a la realización de tales actividades.

Por otra parte, si se observa la tabla 4 puede comprobarse la aparición de nuevas restricciones y de nuevos márgenes de actuación que el legislador "prepara" para el Juez de menores, dejando el juego de la individualización de la respuesta (objetivo esencial de los sistemas de justicia de menores hasta hace muy poco tiempo) para el momento de la ejecución; la cuál, todo sea dicho, también queda afectada en la medida que se prevén restricciones en determinados supuestos para la aplicación de los artículos 14 y 51. 
Tabla 4. Nuevas reglas especiales para la aplicación de medidas a menores infractores

\begin{tabular}{|c|c|c|}
\hline Hecho/Edad & 14-15 años & 16-17 años \\
\hline Delitos graves & $\begin{array}{l}\text { Las medidas pueden } \\
\text { alcanzar hasta } 3 \text { años. Si } \\
\text { fuera una P.S.B.C. podrá } \\
\text { alcanzar las } 150 \text { hs y hasta } \\
12 \text { fines de semana en la } \\
\text { medida de permanencia de } \\
\text { fines de semana }\end{array}$ & $\begin{array}{l}\text { Las medidas pueden } \\
\text { alcanzar hasta } 6 \text { años. Si } \\
\text { fuera una P.S.B.C. podrá } \\
\text { alcanzar las } 200 \text { hs y hasta } \\
16 \text { fines de semana en la } \\
\text { medida de permanencia de } \\
\text { fines de semana* }\end{array}$ \\
\hline $\begin{array}{l}\text { Delitos menos graves, pero } \\
\text { que en su ejecución se haya } \\
\text { empleado violencia } \\
\text { intimidación } \\
\text { personas o } \\
\text { generado grave riesgo para } \\
\text { la vida o la integridad } \\
\text { física }\end{array}$ & $\begin{array}{l}\text { Las medidas pueden } \\
\text { alcanzar hasta } 3 \text { años. Si } \\
\text { fuera una P.S.B.C. podrá } \\
\text { alcanzar las } 150 \text { hs y hasta } \\
12 \text { fines de semana en la } \\
\text { medida de permanencia de } \\
\text { fines de semana }\end{array}$ & $\begin{array}{l}\text { Las medidas pueden } \\
\text { alcanzar hasta } 6 \text { años. Si } \\
\text { fuera una P.S.B.C. podrá } \\
\text { alcanzar las } 200 \text { hs y hasta } \\
16 \text { fines de semana en la } \\
\text { medida de permanencia de } \\
\text { fines de semana* }\end{array}$ \\
\hline $\begin{array}{l}\text { Delitos que se cometan en } \\
\text { grupo o el menor } \\
\text { perteneciere o actuare al } \\
\text { servicio de una banda, } \\
\text { organización o asociación, } \\
\text { incluso de carácter } \\
\text { transitorio, que se dedicare } \\
\text { a la realización de tales } \\
\text { actividades }\end{array}$ & $\begin{array}{l}\text { Las medidas pueden } \\
\text { alcanzar hasta } 3 \text { años. Si } \\
\text { fuera una P.S.B.C. podrá } \\
\text { alcanzar las } 150 \text { hs y hasta } \\
12 \text { fines de semana en la } \\
\text { medida de permanencia de } \\
\text { fines de semana }\end{array}$ & $\begin{array}{l}\text { Las medidas pueden } \\
\text { alcanzar hasta } 6 \text { años. Si } \\
\text { fuera una P.S.B.C. podrá } \\
\text { alcanzar las } 200 \text { hs y hasta } \\
16 \text { fines de semana en la } \\
\text { medida de permanencia de } \\
\text { fines de semana* }\end{array}$ \\
\hline $\begin{array}{l}\text { Asesinato, Homicidio, } \\
\text { Violación y Terrorismo }\end{array}$ & $\begin{array}{l}\text { De } 1 \text { a } 4 \text { años en un centro } \\
\text { cerrado de internamiento }+ \\
3 \text { años de libertad vigilada } \\
\text { (la medida no puede ser } \\
\text { modificada hasta que no } \\
\text { haya transcurrido la mitad } \\
\text { de la duración de la medida } \\
\text { de internamiento impuesta) }\end{array}$ & $\begin{array}{l}\text { De } 1 \text { a } 8 \text { años en un centro } \\
\text { cerrado de internamiento + } \\
5 \text { años de libertad vigilada } \\
\text { (la medida no puede ser } \\
\text { modificada hasta que no } \\
\text { haya transcurrido la mitad } \\
\text { de la duración de la medida } \\
\text { de internamiento impuesta) }\end{array}$ \\
\hline $\begin{array}{l}\text { Delitos de terrorismo que en } \\
\text { el Código penal de adultos } \\
\text { lleve aparejada más de } 15 \\
\text { años de prisión }\end{array}$ & $\begin{array}{l}\text { De } 1 \text { a } 5 \text { años en un centro } \\
\text { cerrado de internamiento }+ \\
3 \text { años de libertad vigilada } \\
\text { (la medida no puede ser } \\
\text { modificada hasta que no } \\
\text { haya transcurrido la mitad } \\
\text { de la duración de la medida } \\
\text { de internamiento impuesta) }\end{array}$ & $\begin{array}{l}\text { De } 1 \text { a } 10 \text { años en un } \\
\text { centro cerrado de } \\
\text { internamiento }+5 \text { años de } \\
\text { libertad vigilada (la medida } \\
\text { no puede ser modificada } \\
\text { hasta que no haya } \\
\text { transcurrido la mitad de la } \\
\text { duración de la medida de } \\
\text { internamiento impuesta) }\end{array}$ \\
\hline
\end{tabular}

* En estos supuestos cuando el caso revistiera extrema gravedad el Juez deberá imponer una medida de internamiento en régimen cerrado de 1 a 6 años+ hasta 5 años de libertad vigilada (la medida no podrá ser modificada hasta que no haya transcurrido el primer año de internamiento) 
Finalmente, el Proyecto también reforma las reglas especiales que se habían previsto para los casos más leves, esto es, las faltas. En el caso de que el menor sea enjuiciado por una falta el Juez de menores no podrá imponer más que una medida de libertad vigilada hasta seis meses, amonestación, permanencia de fin de semana hasta un máximo de cuatro, prestaciones en beneficio de la comunidad hasta 50 horas, privación del permiso de conducir o de otras licencias administrativa hasta un año, la prohibición de aproximarse o comunicarse con la víctima o con aquellos familiares $\mathrm{u}$ otras personas que determine el Juez hasta seis meses, y la realización de tareas socio-educativas hasta seis meses. En este caso el nuevo texto se ha hecho eco de las numerosas críticas que profesionales y analistas habían realizado a las reglas que establece el art. 9.1. y por lo tanto mejora con la nueva previsión.

\subsubsection{La intervención educativa resultante de la aplicación de la LORPM}

En este apartado se va a analizar el resultado de las decisiones adoptadas por el Juez de menores. Para ello se van a utilizar datos correspondientes al sistema de justicia de menores antes de entrar en vigor (año 2000) y datos del sistema una vez que la LORPM entró en vigor (año 2004). El resultado final de esta comparación aparece en la tabla 5 .

Tabla 5. Intervención educativa con la LORPM

\begin{tabular}{|l|c|c|c|c|c|c|}
\hline \multirow{2}{*}{} & \multicolumn{3}{|c|}{ LORJM (2000) } & \multicolumn{3}{c|}{ LORPM (2004) } \\
\cline { 2 - 7 } & $\mathrm{N}$ & $\%\left({ }^{1}\right)$ & $\%\left(^{2}\right)$ & $\mathrm{N}$ & $\%\left({ }^{1}\right)$ & $\%\left({ }^{2}\right)$ \\
\hline Amonestación & 2.015 & $25,4 \%$ & $10 \%$ & 1.719 & $8,4 \%$ & $4,8 \%$ \\
\hline Intervención medio abierto: & $\mathbf{4 . 3 4 9}$ & $\mathbf{5 4 , 8 \%}$ & $\mathbf{2 1 , 6 \%}$ & $\mathbf{1 3 . 2 5 3}$ & $\mathbf{6 4 , 9 \%}$ & $\mathbf{3 7 , 2 \%}$ \\
\hline Tareas educativas & 0 & $0 \%$ & $0 \%$ & 0 & $0 \%$ & $0 \%$ \\
\hline PSBC & 1.689 & 21,35 & $8,4 \%$ & 6.363 & $31,1 \%$ & $17,9 \%$ \\
\hline Convivencia con familia & 4 & $0,04 \%$ & $0,02 \%$ & 51 & $0,2 \%$ & $0,1 \%$ \\
\hline Libertad Vigilada & 2.563 & $32,3 \%$ & $12,7 \%$ & 6.205 & $30,4 \%$ & $17,4 \%$ \\
\hline Tratamiento Ambulatorio & 93 & $1,2 \%$ & $0,5 \%$ & 634 & $3,1 \%$ & $1,8 \%$ \\
\hline Asistencia a Centro de Día & 0 & $0 \%$ & $0 \%$ & 0 & $0 \%$ & $0 \%$ \\
\hline Intervención en centro: & $\mathbf{1 . 4 8 5}$ & $\mathbf{1 8 , 7 \%}$ & $\mathbf{7 , 4 \%}$ & $\mathbf{4 . 6 4 6}$ & $\mathbf{2 2 , 7 \%}$ & $\mathbf{1 3 \%}$ \\
\hline I. abierto/semi-abierto/terapéutico & 643 & $8,1 \%$ & $3,2 \%$ & 2.992 & $8,1 \%$ & $8,4 \%$ \\
\hline Internamiento centro cerrado & 842 & $10,6 \%$ & $4,2 \%$ & 1.654 & $14,6 \%$ & $4,6 \%$ \\
\hline Privativas de derechos & $\mathbf{6}$ & $\mathbf{0 , 1 \%}$ & $\mathbf{0 , 0 3 \%}$ & $\mathbf{1 0 8}$ & $\mathbf{0 , 5 \%}$ & $\mathbf{0 , 3 \%}$ \\
\hline No consta & $\mathbf{7 9}$ & $\mathbf{1 \%}$ & $\mathbf{0 , 4 \%}$ & $\mathbf{7 1 0}$ & $\mathbf{3 , 5 \%}$ & $\mathbf{2 \%}$ \\
\hline Total medidas & 7.934 & $100 \%$ & $39,43 \%$ & 20.436 & $100 \%$ & $57,3 \%$ \\
\hline TOTAL ACTUACIONES & 20.143 & & $100 \%$ & & 35.611 & 100 \\
\hline
\end{tabular}

Fuente: INE $\left(^{1}\right)$ Porcentaje respecto al total de medidas

$\left({ }^{2}\right)$ Porcentaje respecto al total de expedientes

Revista Española de Investigación Criminológica

Artículo 4, Número 4 (2006) $\quad$ www.criminología.net

ISSN: $1696-9219$ 
La primera conclusión que cabe plantearse es que con la LORPM el número de expedientes en los que se ha impuesto una medida educativa como respuesta al hecho delictivo ha aumentado respecto a lo que ocurría con la LORJM. En concreto en el año 2000 el número de medidas aplicadas representó un 39,43\% respecto del total de actuaciones, con la nueva ley ese porcentaje aumenta a un 57,3\%.

Este aumento debe atribuirse a una consecuencia directa de la nueva regulación. La LORPM limita la posibilidad de desjudicializar el expediente sólo a aquellos delitos menos graves y a las faltas. Por lo tanto a pesar de que el interés del menor aconseje lo contrario, cuando se trate de un delito grave la Ley obliga a que el menor sea sometido a un juicio y se intervenga con él a través de una medida educativa adoptada por el Juez. Esto es, evita que en determinados supuestos sea el interés del menor el que condicione la respuesta, ya que será la especial gravedad de los hechos la que exclusivamente obligue a intervenir.

Dentro de ese mayor intervencionismo el siguiente dato que se quiere resaltar es el considerable aumento del empleo de la medida de internamiento. De un 18,7\% aplicado en el año 2000, se pasa a un 22,7\% en el año 2004. En respuesta a la hipótesis planteada se pueden señalar las siguientes explicaciones.

Por un lado, la regulación tan precisa que el legislador realiza sobre los supuestos en los que procede el internamiento ha podido motivar el aumento en su empleo. En este sentido, si esta explicación pudiera confirmase significaría que con la anterior legislación determinados supuestos graves obtuvieron una respuesta de intervención comunitaria por ser considerada más beneficiosa en atención a la situación psicosocial del menor. Esto es, la mayor flexibilidad con la que contaron los Jueces de menores a la hora de adoptar una medida habría potenciado en mayor medida la apuesta por la intervención comunitaria, que aquellos parecían preferir. En este sentido el mayor encorsetamiento a la hora de determinar la medida que se produce con la LORPM, habría hecho primar el criterio del legislador frente al del aplicador obligando a adoptar medidas de internamiento, allí donde el Juez podía preferir adoptar una medida comunitaria. 
Por otro lado, es necesario tener en cuenta que la entrada al sistema de sujetos de mayor edad, ha traído al mismo situaciones más graves que demandan una intervención más intensiva (Fernández Molina, en prensa).

Finalmente hay otra explicación que no puede obviarse y que podría justificar gran parte del aumento de las medidas privativas de libertad. El hecho de que la LORPM viniera acompañada de una mayor dotación presupuestaria ha supuesto que se hayan creado más centros de internamiento, por lo tanto si el recurso existe las probabilidades de que se utilice son mayores.

En relación con las medidas comunitarias los datos oficiales aportan una información bastante sorprendente. A pesar de contar con un catálogo que amplía el tratamiento en el ámbito comunitario a un mayor número de medidas, en la práctica siguen aplicándose las dos medidas que ya existían anteriormente, la libertad vigilada $(30,4 \%)$ y la PSBC $(31,1 \%)$. Esto es, en los primeros años de aplicación práctica de la Ley no se ha producido la esperada diversificación entre las medidas de intervención comunitaria. De hecho la aplicación de las dos nuevas medidas no se ha hecho efectiva $^{19}$.

Detrás de la no aplicación de las nuevas medidas pueden encontrarse varias razones, en primer lugar se podría señalar la existencia de cierta confusión en relación con estas dos nuevas medidas, sobre las que no se ha sabido interpretar muy bien cuál es su verdadero alcance. También es posible que entre las causas de su no aplicación se encuentren razones de recursos, esto es, si no existen los Centros de día o no hay personal suficiente para llevar a cabo intervenciones educativas puntuales, difícilmente se van a poder aplicar estas medidas.

Por último, existe otra razón de peso detrás del escaso impacto de estas medidas, que puede ser atribuido a un error en la actuación del legislador que si quería garantizar una intervención comunitaria más amplia y más diversificada, lo que debería haber

${ }^{19}$ En relación con estos datos parece sospechoso que no exista durante el año 2004 la aplicación de ninguna medida de Asistencia a Centro de Día ni de Tareas socioeducativas, se intuye que puede haber algún problema en la recogida de información detrás de este dato, en el que, por ejemplo, en los resultados del apartado "no consta" se esté recogiendo el número de medidas de nueva aplicación. De hecho un informe realizado por el Ministerio de Trabajo y Asuntos Sociales reveló que en el año 2003 la medida de realización de tareas socioeducativas se había aplicado en un $4 \%$ de las ocasiones mientras que la medida de asistencia a centro de día se había aplicado en un 0,5\% (Fernández Molina y Rechea, 2006).

Revista Española de Investigación Criminológica

Artículo 4, Número 4 (2006) $\quad$ www.criminología.net

ISSN: $1696-9219$ 
realizado más que un catálogo muy amplio de medidas, sería un procedimiento flexible que permitiera individualizar la intervención a la especial situación del menor, en lugar de la encorsetada regulación que realiza. En realidad, el éxito de la intervención comunitaria y su diversificación sólo se va a producir si existe una cantidad de recursos y programas suficientes, adecuados a la realidad de cada Comunidad autónoma, que permitan una intervención individualizada a la situación psicosocial del menor.

En este sentido se podría interpretar, que precisamente como consecuencia de la dotación de mayores recursos que ha supuesto la Ley en la gran mayoría de Comunidades Autónomas, el porcentaje de amonestación ha descendido, de aplicarse en un $25,4 \%$ de las ocasiones en que se aplicaba una medida ha pasado a aplicarse en un $8,4 \%$. Corroborándose así la explicación de que el uso desmedido que de esta medida se ha realizado durante tantos años en la jurisdicción de menores en España, se debía en gran medida a la falta de medios para poder llevar a cabo otras intervenciones educativas (Rechea Alberola y Fernández Molina, 2003).

Sin embargo, todavía queda mucho camino por andar en la intervención comunitaria, aunque se han creado los recursos, se necesita una actuación más coordinada que garantice una mayor eficacia y que efectivamente se convierta en una intervención preventiva. Asimismo, que duda cabe que la rígida regulación que finalmente ha resultado tras las sucesivas reformas está dificultando en gran medida experimentar con las alternativas a la privación de libertad, ya que la Ley obliga en determinados supuestos a pasar un tiempo mínimo en internamiento.

\section{Conclusiones}

Tal y como se decía al principio del artículo, el sistema de justicia de menores que define la LORPM se ha consolidado durante estos cinco años de vigencia de la misma. Gracias al impulso que supuso la publicación de este texto legislativo se han ido afianzando en nuestro país unas dinámicas, que permiten a sus profesionales llevar a cabo una actuación especializada con los menores infractores, muy similares a las que se están aplicando en la gran mayoría de los países desarrollados y que tratan de buscar un equilibrio entre la educación y el castigo. 
No obstante, y también desde el primer momento de su publicación quedaron patentes las dudas sobre la posibilidad de aplicar este sistema especial a un sector determinado de la población: los menores de más edad, que cometen delitos graves o son reincidentes. Sin embargo, y a pesar del empeño del legislador por endurecer la respuesta a este núcleo duro, la práctica judicial y el criterio de los profesionales, al menos en los primeros años de aplicación, parecía primar sobre la voluntad legislativa. Así, y gracias al margen de discrecionalidad y a la flexibilidad que preside este sistema, en las decisiones judiciales seguía prevaleciendo un modo de entender la respuesta a los menores infractores fundamentada, esencialmente, en la educación y el interés del menor.

Sin embargo, los últimos resultados conocidos de la aplicación práctica de la Ley nos hacen pensar que las tendencias están cambiando y que es posible que la práctica judicial haya acabado contaminándose del clima más punitivo que parece impregnar a la ciudadanía. Además, consideramos que los nuevos criterios para la aplicación de las medidas y la incorporación definitiva de la víctima y sus intereses en el sistema de justicia juvenil pueden acabar finalmente socavando la esencia del mismo, en la medida en que sus dos premisas básicas, individualización y primacía del interés del menor, están perdiendo su fuerza inicial.

\section{Referencias}

- Bailleau, F. y Cartuyvels, Y (2002)《Introduction». Déviance et Societé, 26, 279-282.

- Barberet, R. Rechea, C. y Montañés, J. (1994) "Self-Reported Juvenile Delinquency in Spain: Results from the Spanish Survey of the International SelfReport Delinquency Project." In Jünger-Tas, Terlouw y Klein (Coords.) Delinquent Behaviour Among Young People in the Western World. Amsterdam: Kugler.

- Barberet, R. (2001) "Youth Crime in Western Europe: Will the Old World Imitate the New?." In Susan O. White (Ed.) Handbook of Act and Social Science: Youth and Justice. New York: Plenum.

- Bernuz Beneitez, M.J. y Fernández Molina, E. (2006) «La justice des mineurs en Espagne comme exemple d'un modele de gestion du risque ». Logiques sociales. Octobre. Paris: L'harmattan 
- Fernández Molina, E. (2002) "La valoración del interés del menor en la LO $5 / 2000$, de 12 de enero, reguladora de la responsabilidad penal de los menores" Martín Ostos, J (Dir.) Anuario de Justicia de Menores, 2, 55-77.

- Fernández Molina, E (en prensa) Entre la educación y el castigo: un análisis de la justicia de menores en España. Valencia: Tirant lo Blanch.

- Fernández Molina, E y Rechea Alberola, C (2005) "Policies transfer: the case of juvenile justice in Spain". European Journal on Criminal Policy and Research. Vol. 11. No 1, p. 51-76.

- Fernández Molina, E. y Rechea Alberola, C. (2006) "La aplicación de la LORPM en Castilla-La Mancha: nuevos elementos para el análisis de los sistemas de justicia de menores". Revista de Derecho Penal y Criminología. Núm. 18.

- Garrido Genovés, V (1995) "La intervención con jóvenes infractores en medio cerrado" en Justicia con menores y jóvenes. Centro de Estudios Jurídicos de la Administración de Justicia. Col. Cursos. Vol. 17. Ministerio Justicia e Interior. Madrid. pp.159-165.

- Garrido Genovés, V (2001) "Los fundamentos científicos de la Ley de responsabilidad del penal menor". Revista de las Facultades de Derecho y Ciencias Económicas y Empresariales de ICADE. Núm. 53. pp.13-30.

- Gatti, U (1999) "Sistema italiano de justicia para menores de edad" GiménezSalinas, E. (Dir.) Legislación de menores en el siglo XXI: análisis de derecho comparado. Estudios de Derecho Judicial. No 18. Ed. CGPJ. Madrid. pp. 271304.

- Jesionek, U (1999) “Jurisdicción de menores en Austria”. Giménez-Salinas, E. (Dir.) Legislación de menores en el siglo XXI: análisis de derecho comparado. Estudios de Derecho Judicial. No 18. Madrid: CGPJ. pp. 51-72.

- Jueces y Fiscales de menores (2003) Conclusiones elaboradas los días días 10, 11 y 12 de noviembre.

- Ornosa Fernández, R (2003) Derecho penal de menores. 2a Edición. Barcelona: Bosch. $1^{\text {a }}$ Edición 2000.

- Rechea Alberola, C. y Fernández Molina, E. (2003) "Juvenile justice in Spain: Past and Present". Journal of Contemporary Criminal Justice. Vol. 19 (4). pp. 384-412.

- Rechea Alberola, C. y Fernández Molina, E. (2006) "Continuity and change in the Spanish Juvenile Justice System” en Junger-Tass, J y Decker, S (Eds.) Handbook of Juvenile Justice. Ed. Kluwer/Springer.

- Rössner, D. (1999). "El Derecho penal de menores en Alemania con especial consideración de los adolescentes". Giménez-Salinas, E. (Dir.) Legislación de 
menores en el siglo XXI: análisis de derecho comparado. Estudios de Derecho Judicial. No 18. Madrid: CGPJ. pp. 305-328.

- Schüler-Springorum, H. (1999). "Juvenile Justice and the 'Shift to the Left"'. European Journal on Criminal Policy and Research, vol. 7, 3, pp. 353-362. 